\title{
Discípulos de Paulo Freire e o compromisso com a educação emancipadora
}

\author{
ANDRÉIA NUNES MILITÃO* \\ Universidade Estadual de Mato Grosso do Sul, Dourados-MS, Brasil.
}

$\mathrm{N}$ o limiar de completar 100 anos do nascimento de Paulo Freire, a Retratos da Escola apresenta a seus leitores e leitoras reflexões sobre este autor, reconhecido mundialmente por suas inestimáveis contribuições ao desenvolvimento de práticas educacionais voltadas a uma sociedade mais justa e igualitária.

Embora aclamado como Patrono da Educação Brasileira, por meio da Lei n.․ 12.612 de 2012 no Governo Dilma Rousseff, o educador conviveu com perseguições durante a vida e mesmo após a morte continua a sofrer duras críticas.

A resistência a Paulo Freire já vem de longa data, desde o fim da década de 1950 e início de 1960, quando o educador, ao conceber a educação popular, concretiza iniciativas de conscientização política do povo, particularmente das classes sociais excluídas e oprimidas. Suas ideias foram já então entendidas como subversivas pelo regime militar. Atualmente, as manifestações contra ele revelam que os setores conservadores continuam tão reacionários quanto na época da ditadura, sobretudo no campo educacional.

Tendo isso em vista, para a seção Entrevista deste número, convidamos Cristiano Amaral Garboggini di Giorgi, Dagmar Maria Leopoldi Zibas e Rudá Guedes Moises Salerno Ricci, três ex-alunos/as de Paulo Freire, do período em que o educador ministrou aulas no Programa de Pós-Graduação em Educação da Pontifícia Universidade Católica de São Paulo (PUC-SP), no início da década de 1980, para reflexionarem acerca das seguintes questões: Por que Paulo Freire ainda incomoda a muitos/as? O que revelam os discursos, pretéritos e atuais, contra este pensador? Qual é a importância de Paulo Freire para a educação e para a mudança civilizacional que se faz necessária em decorrência do acúmulo de crises que vivemos atualmente?

De antemão, gostaríamos de registrar nossa gratidão aos entrevistados/a pela disponibilidade em compartilhar conosco os significados de ser aluno/aluna de Paulo Freire.

* É graduada em História e Pedagogia. Possui mestrado em História e doutorado em Educação, ambos pela Universidade Estadual Paulista Júlio de Mesquita Filho. É professora da Universidade Estadual de Mato Grosso do Sul, docente do Programa de Pós-Graduação em Educação da Universidade Federal da Grande Dourados e líder do Grupo de Estudos e Pesquisa Políticas Educacionais e Formação de Professores (GEPPEF). E-mail: $<$ andreianunesmilitao@gmail.com>. 


\section{Conte-nos um pouco sobre como foram os caminhos que o/a levaram a ser aluno/ aluna de Paulo Freire?}

Cristiano Di Giorgi: Eu fiz minha graduação em física. Sempre fui muito bom em matemática e física, cheguei a ser capa de um jornal de grande circulação como "Mini-Gênio" por dominar tópicos de matemática avançada aos 9 anos de idade. Assim, foi natural seguir um curso nesta área e eu pretendia ser um físico, pesquisador, um cientista deste campo. Mas, com 19 anos comecei a participar de um trabalho de educação de adultos e me apaixonei por educação. Então, meu destino começou a mudar. Acabei o bacharelado em física, mas fiz também a licenciatura. Comecei a dar aulas e, em 1982, comecei o mestrado em educação na PUC-SP, que escolhi em grande parte para ter a oportunidade de ser aluno de Paulo Freire. No contato pessoal com Paulo Freire, era possível sentir a profunda coerência entre o que ele pregava e o que ele fazia e vivia. Esta é a principal razão pela qual ele tocava tão profundamente as pessoas.

Dagmar Zibas: Fui a primeira pessoa da família a entrar para a universidade. E isso só aconteceu pouco antes que eu completasse 30 anos de idade. Nos meus 18 anos, ou seja, em 1954, o curso superior não fazia parte dos projetos da imensa maioria das meninas de classe média. Terminar o curso normal, para ser professora primária, já era uma grande vitória. A universidade era apenas para poucos ou para a elite. Mas nem a prestigiosa Escola Normal pude fazer. Isso porque, nesse tempo, as candidatas ao curso (a carreira já era predominantemente feminina) passavam por um exame médico rigoroso. Um alto grau de hipermetropia impediu minha matrícula. Fiz, então, escola técnica de secretariado. Trabalhando na profissão, finalmente, aos 28 anos, ingressei no curso noturno de pedagogia do Mackenzie. Nem tentei a Universidade de São Paulo (USP) porque, na época, aquela instituição não ofertava o curso no período noturno. Entretanto, sem experiência no magistério, o diploma de pedagoga não era suficiente para o início na nova carreira. Prossegui, então, minha formação na área da educação, com mestrado em psicologia da educação na PUC-SP. Posteriormente, ingressei na Fundação Carlos Chagas como assistente de pesquisa, e, em 1994, aos 58 anos, veio a conclusão do doutorado na USP. Enfim, uma carreira acadêmica bastante atípica, principalmente em vista do tardio ingresso na universidade. Essa defasagem escolar, digamos assim, me deu o privilégio de conseguir uma disputadíssima vaga no primeiro curso que Paulo Freire ministrou na pós-graduação da PUC-SP, em 1980. Estávamos vivendo um clima de euforia em vista da relativa distensão política e da volta dos exilados pela ditadura militar. Havia muita ansiedade, até um certo frenesi, um certo deslumbramento cercando a figura de Paulo Freire. Um perseguido político, uma personalidade já proeminente no exterior e que, finalmente, poderia ser ouvida e vista entre nós. 
Rudá Ricci: Sou sociólogo e presidente do Instituto Cultiva (www.institutocultiva. com.br). Também sou membro da coordenação da Articulação Brasileira da Economia de Francisco e Clara e sou coordenador do Pacto Educativo Global no Brasil, duas articulações mundiais lideradas pelo Papa Francisco. Ingressei na PUC-SP em 1980. Paulo Freire tinha sido convidado por Dom Paulo Evaristo Arns, no ano anterior, a dar aulas naquela instituição. Eu assistia algumas aulas meio a contragosto e, um dia, decidi sair da sala de aula e fui assistir a aula de Paulo Freire, no $4^{\circ}$ andar do prédio novo da universidade. $\mathrm{O} 4^{\circ}$ andar era o local da pós-graduação. Assisti uma ou outra aula de Florestan Fernandes e Décio Pignatari. Mas, comecei a frequentar com mais assiduidade as aulas de Paulo Freire. Num desses dias, ao terminar a aula, Freire pediu para conversar comigo. Não vou dizer que fiquei preocupado porque no alto dos 17 ou 18 anos, a petulância é quase sempre uma marca registrada. Paulo disse mais ou menos o seguinte: "nem vou perguntar se você está faltando nas aulas de graduação, já que você tem cara de calouro. Mas, se vai assistir minhas aulas, terá que se comportar como os outros mestrandos: terá que ler todos os textos, participar dos seminários e produzir os trabalhos". Topei. Acho que foi um teste. E devo ter passado no teste porque, pouco tempo depois, ele me convidou para participar de seminários abertos, nas manhãs de sábado, num quase-auditório, a sala 333. Era impressionante. Gente do mundo todo, gente sentada no chão e Paulo lendo "A Dialética do Concreto", de Karel Kosik, com uma calma, dando colorido a cada frase a partir de outros autores, teorias e de sua experiência enciclopédica. Paulo comentava, por sábado, praticamente um parágrafo do livro. No começo, eu ficava angustiado, contando os anos que levaríamos para ler o livro todo. Mas, aos poucos, aprendi o que era ler, saborear, trabalhar os meandros de um livro e ir além dele. Algo parecido com a proposta de portfólio de Fernando Hernandez. Um dia, disse isso para Paulo: "você me ensinou a ler". Tempos depois, passei a fazer parte da equipe de educadores populares que alfabetizavam empregadas domésticas e porteiros dos prédios domiciliares do entorno da PUC-SP. O passo seguinte foi conhecer Pedro Pontual, um importantíssimo educador popular que deu aulas a respeito deste tema no Sedes Sapientae, um instituto próximo da universidade. Paulo era um amigo, bem rigoroso e afetuoso, o que nem sempre são aliados. Ele nos ensinava a ter autocontrole para não falar de maneira que o interlocutor não entendia (e portanto, não tinha como criticar ou problematizar o que dizíamos), que deveríamos ouvir as palavras e valores do educando, que não deveríamos ser populistas (e fingir que tínhamos o mesmo poder que o educando), que tínhamos que nos esforçar para construir o conhecimento com calma e coletivamente (sem pressa, sem atropelar, mediando as discussões e reflexões, mediando divergências entre educandos). Mais tarde, nos reencontramos no governo Erundina. O que caracterizava Paulo era o rigor, o gosto pelas palavras (ele estendia o som das sílabas como se estivesse provando uma iguaria), a preocupação com o estabelecimento de uma relação cuidadosa e dialógica com o educando e a disponibilidade. 


\section{Na condição de aluno/aluna de Paulo Freire, quais foram os aprendizados que mais lhe marcaram?}

Cristiano Di Giorgi: Em primeiro lugar, procurar conhecer bem os alunos e tomar como ponto de partida suas vivências. Lembro que Paulo Freire começou o seu curso perguntando a cada um de nós se tínhamos atividade pedagógica, qual era e nos pedindo que falássemos sobre nossa prática e nossas inquietações a respeito dela. Ele organizou o programa da disciplina a partir disto. Em segundo lugar, aprendi que é muito melhor ler bem e em profundidade os textos e livros mais importantes do que ler muitíssimas coisas meio por cima. Freire indicava poucas leituras, mas se aprofundava em cada uma como nenhum outro professor que conheci. Terceiro, a importância do diálogo: Freire estabelecia realmente um clima dialogal em sala de aula e percebíamos claramente que ele de fato também aprendia conosco, à medida que nós aprendíamos com ele e com os colegas. Em quarto lugar, aprendi muito sobre realidades que eu desconhecia, como as africanas, das quais Freire falou bastante, descrevendo suas experiências no continente.

Dagmar Zibas: O mestre não decepcionou seus alunos. Muito pelo contrário. Nossa grande expectativa foi excedida. Sua alegria de estar, finalmente, lecionando em sua língua, para seus compatriotas, sua compreensível disposição de nos contar as aprendizagens, as agruras e as alegrias vividas além-mar temperavam seu grande empenho em nos desafiar a contestar suas teses, a discutir os pressupostos de suas afirmações, em dialogar, em ouvir nossas opiniões. Todavia, naquele momento, por incrível que pareça, já havia, na própria PUC-SP, o gérmen da ideologia que viríamos a conhecer, muito recentemente, como o movimento político-pedagógico reacionário, autodenominado "escola sem partido". Sim, esse embrião da "escola sem partido" estava se formando na pós-graduação da PUC-SP, em 1980, e sua representante maior era a prof ${ }^{a}$. drª . Guiomar Namo de Mello. Essa postura política e ideológica de Mello foi consolidada mais tarde, em 1990, em seu livro Social Democracia e Educação: teses para discussão, publicado pela Cortez Editores Associados em 1990, mais especificamente no capítulo intitulado Escola não é partido. Eu tive o prazer de escrever uma resenha sobre esse livro de Mello, texto em que procurei mostrar a falácia de suas teses. Essa resenha foi publicada no número 74 da Cadernos de Pesquisa, revista da Fundação Carlos Chagas, em agosto de 1990. Então, desde 1980, mesmo na euforia de seu retorno do exílio, Paulo Freire já sentia, dentro da própria instituição que o acolheu com entusiasmo e carinho uma oposição acadêmica, ideológica e política, que se refletia em debates em salas de aula e até nos corredores da PUC-SP. Nesse contexto já conflitivo, aprendi com Paulo Freire que a educação libertadora sempre encontrará, em qualquer conjuntura e em qualquer contexto, obstáculos políticos e ideológicos, pois é a formação que permite ao educando e à educanda ler o mundo em todas as suas relações de opressão, desigualdade e injustiça. São essas relações que as classes dominantes 
e seus intelectuais orgânicos lutam para camuflar, revestir, esconder. Aprendi, também, que essa posição ideológica, conservadora e perversa, deve ser enfrentada, no campo teórico, com um aprofundamento de sólida fundamentação histórica, sociológica, filosófica e pedagógica, e, no campo da prática pedagógica, com o desenvolvimento do método que permite ao professor ensinar e, ao mesmo tempo, aprender com seus alunos a leitura do mundo real e os caminhos para a construção de uma sociedade mais justa.

Rudá Ricci: Primeiro, a atenção e o respeito à cultura e vivência dos outros. Olhar sem preconceito, mas como curiosidade, inclusive, técnica. Segundo, o rigor técnico para criar uma relação de confiança, mas, também, de reflexão em todo processo educativo, $\mathrm{o}$ que ele denominava de "ad-mirar", promover o olhar de fora sobre si, sobre as escolhas, as práticas. Uma terceira lição foi a administração do tempo, sem pressa, no ritmo do outro. Disso, havia alguns desdobramentos: de um lado, o "silêncio tático", outro conceito importante criado por ele. Trata-se do autocontrole do educador para não fazer críticas sem que o espaço de confiança e diálogo esteja plenamente estabelecido. Se você, no ímpeto de fazer o outro refletir sobre algum preconceito ou ato descabido, se impõe antes que o espaço de diálogo esteja consolidado, você pode acabar intimidando ou fazendo o educando se tornar submisso ou, ainda, abandonar a sala de aula. Então, é preciso avaliar o momento da apresentação de sua posição, para que o outro a acolha como uma postura diferente da sua, não como uma reprimenda. Porque o educador precisa ser honesto e apresentar seu pensamento e seu posicionamento. O segundo desdobramento é o que Bertrand Russell sugeriu ser o "ócio da mente". Ócio, para Russell, não é vagabundagem, mas o tempo necessário para, por exemplo, um fruto ficar maduro, doce e aromático. A mente funciona também assim: precisa de tempo para refletir, para assimilar sem se doutrinar. Somente assim podemos construir o autogoverno, a famosa autonomia. Uma das referências mais importantes de Freire era a fenomenologia, os diversos momentos em que um indivíduo percebe e sente o que o rodeia, dialoga com outros, estranha ou duvida, até construir um juízo sobre o que sentiu. Este processo é o processo humano de construção do conhecimento e, muitas vezes, os gestores da educação esquecem que somos humanos e decidem acelerar ou induzir à resposta final. Freire sempre nos lembrava deste timing cognitivo-afetivo. Algo que Antonio Damasio, neurologista de Iowa, veio comprovar mais tarde: a íntima relação entre emoção e o sensível com a razão e a lógica. Foram muitas lições, mas destaco estas porque nem sempre se fala das preocupações freireanas. Normalmente, destaca-se o engajamento social da e pela educação e se esquece do método, do processo educativo, que foi uma das maiores contribuições de Paulo Freire. 


\section{Na sua opinião, por que e a quem a obra Paulo Freire incomoda?}

Cristiano Di Giorgi: Paulo Freire tem uma proposta de educação libertadora, que busca o fim das opressões. Então, de forma bem simples e direta, ele incomoda principalmente aqueles que estão comprometidos com a manutenção das injustiças sociais, que não querem o fim das opressões, que não querem a libertação dos oprimidos. Sem dúvida nenhuma, estes são os principais incomodados e os grandes inimigos de Freire. Mas há outros a quem ele também incomoda. Ele incomoda também aqueles que, ainda que não estejam diretamente envolvidos na manutenção das opressões, alimentam a ingênua visão da neutralidade da educação. Eu ousaria acrescentar que incomoda também aqueles educadores que, embora progressistas, têm dificuldade em assumir um comprometimento autêntico, uma comunhão e uma aproximação que geram um verdadeiro renascer. A coerência com a pedagogia freiriana é muito exigente. Afinal, como afirma Freire, "é fundamental diminuir a distância entre o que se diz e o que se faz, de tal forma que, num dado momento, a tua fala seja a tua prática". Isto não é fácil e muitos educadores se sentem incomodados por exigência tão radical. Freire defende que os homens são seres da busca e a sua vocação ontológica é "ser mais", humanizarem-se. Isto exige um esforço constante do educador para possibilitar aos educandos "serem mais"; e também o educador precisa, ele próprio, estar empenhado nesta busca, nesta realização da sua vocação ontológica.

Dagmar Zibas: A educação freireana é um instrumento pedagógico e político de empoderamento dos oprimidos. Reúne o princípio filosófico-educacional e a metodologia pedagógico-didática que melhor traduzem a preocupação gramsciana de construção de uma cultura contra-hegemônica, cultura que rompa o senso comum e demarque nitidamente o conflito de interesses que move a sociedade capitalista. O desvendamento dessas relações de classe, obviamente, não interessa aos detentores dos privilégios, não interessa aos opressores. Daí vem essa obsessão histórica, e também muito atual, de desvirtuar, destruir, vilipendiar não só a obra, mas também a figura emblemática de Paulo Freire.

Rudá Ricci: Incomoda porque desenvolveu uma teoria absolutamente oposta à doutrinação. O objetivo educacional para Paulo Freire é a construção da autonomia. Autonomia não é liberdade total, ao contrário, é a capacidade que temos de nos localizar no mundo e sabermos nos controlar para conviver com o diferente, mas a partir de princípios éticos (lembremos que nem toda moral é ética). Há mais: Paulo Freire revelava que a massificação da educação taylorista não educa, mas treina a partir de um padrão pré-estabelecido que é plasmado no currículo prescritivo, aquele que não se importa com a vida e a cultura do educando. Aliás, a concepção taylorista despreza a existência do educando antes de pisar numa escola porque acredita que sociedade deve ser domada e civilizada pelo educador. Ora, tais 
sugestões se chocam com uma lógica de poder e de dominação. A mera crítica ao padrão dominante de educação cria um incômodo imenso porque elimina instâncias de controle e padronização, altera sistemas de avaliação classificatória, reorganiza os tempos (sugerindo a superação dos módulos-aula de 50 minutos), redefine o tempo do professor (que passa a ser considerado um pesquisador dos processos de desenvolvimento dos educandos), desmonta todo um sistema educacional montado nas certezas exógenas à vida do educando. Realmente, quem está no topo da hierarquia social e de poder não tem muito como se alegrar com as teorias freireanas e continuar fazendo o que faz.

\section{O que revelam os atuais discursos contra este autor?}

Cristiano Di Giorgi: Revelam sobretudo o ódio da classe dominante a ele e como esta é capaz de, muitas vezes, fazer com que setores oprimidos assumam o discurso dos dominantes. Mas revelam também um grande desconhecimento sobre ele. É preciso que as universidades, nos cursos de pedagogia, nas licenciaturas e nos programas de pós-graduação em educação e outras ciências humanas, busquem difundir as ideias de Freire, coisa que tem ocorrido muito pouco.

Rudá Ricci: Que as teorias de Paulo Freire estão vivas. Ninguém ataca alguém que deixou de existir ou ter importância para nós. Trata-se de uma disputa de poder. Perceba que a violência verbal é absolutamente reveladora do incômodo com Paulo Freire, que é o terceiro teórico mais citado em trabalhos acadêmicos no mundo. A Finlândia, considerado o país com a melhor educação do mundo, se baseia em suas ideias desde o início da revolução educacional que adotou. Paulo Freire e Anísio Teixeira são referência por lá. E o que os que o atacam sugerem como contraponto? A doutrinação ultraconservadora. Então, há uma aposta na ignorância e desconhecimento do que Paulo Freire propôs: sustentam que Paulo teria dito o inverso do que realmente diz. Uma técnica discursiva desonesta, mas que segue as orientações de Schopenhauer de como ganhar uma discussão por diversionismos, pela desorientação e manipulação do que o seu interlocutor diz, sempre, sem ter qualquer razão. O que demonstra a força da educação. Se não fosse algo tão poderoso, para que disputar com o patrono da educação brasileira?

Qual é a importância de Freire, neste momento, para a educação e para a mudança civilizacional que se faz necessária pelo acúmulo de crises que vivemos?

Cristiano Di Giorgi: Freire é hoje essencial, pois na educação e na vida social precisamos mais do que nunca de humanização, diante de um sistema social que se tornou crescentemente desumanizador. Freire é o autor que melhor descreve este processo de humanização e o que melhor indica caminhos para chegarmos a ela. Qualquer 
transformação educacional e social hoje depende crucialmente das pessoas se conscientizarem de seu potencial humanizador e encontrarem caminhos para realizá-lo. Discursos abstratos sobre uma nova educação ou uma nova sociedade que não despertem nas pessoas esta sensação de que podem ser melhores, mais felizes e mais humanas não têm nenhum efeito. Freire, como nenhum outro autor, estabelece esta conexão entre humanização de cada indivíduo e as mudanças que se almejam.

Dagmar Zibas: Para responder essa questão, é necessário lidar agora com uma falácia histórica, aliás já ventilada por Guiomar Namo de Mello no livro citado aqui. Na atualidade, a mesma falácia é reproduzida pelo Governo Bolsonaro e seu séquito de mal formados e mal intencionados, quando insistem em atribuir o fracasso do ensino básico no Brasil ao pretenso uso extensivo do método Paulo Freire em nossas escolas. Ora, quem conhece o sistema público de ensino - fundamental e médio - sabe muito bem que, infelizmente, o método freireano é praticamente desconhecido da absoluta maioria dos professores desses níveis de ensino. Portanto, não é usado por esses profissionais, grande parte dos quais é mal formada e amarrada a condições precaríssimas de trabalho e sobrevivência. Assim, atribuir a Paulo Freire o fracasso da escola básica pública é manifestação de má fé ou de total desconhecimento da estrutura físico/pedagógico/administrativa e da dinâmica do nosso sistema educacional ou de ambos. Isso posto, devemos explicitar que este é o momento mais trágico da vida nacional desde o fim da ditadura militar. $\mathrm{O}$ núcleo ideológico do atual desgoverno declarou guerra ao pensamento iluminista, à ciência, à cultura, às humanidades, aos direitos humanos, à imprensa livre, à preservação do meio ambiente, às minorias e aos trabalhadores mais pobres. Estamos envolvidos num tsunami de retrocesso político e social sem precedentes em passado recente. Esse pesadelo não está só sobre nossas cabeças, mas pesa sobre diversas regiões do mundo. A obra de Paulo Freire é um marco histórico e perdurará enquanto houver sociedades injustas, desiguais, mantenedoras de privilégios de poucos, e que negam os direitos, a voz e a vez da maioria, dos mais pobres e oprimidos.

Rudá Ricci: Paulo Freire conseguiu unificar processos educacionais com processos cognitivo-afetivos, articulou a construção da autonomia com engajamento social, relacionou imperativos éticos com métodos pedagógicos e nos ensinou a alfabetizar em 45 dias. Ora, não é isso que realmente precisamos no momento em que tantos afirmam que adolescentes não conseguem ler e escrever corretamente, que tantos criticam uma sociedade cada vez mais opressiva que nos leva à exaustão pela exigência de um desempenho perfeito em tudo que fazemos? Paulo Freire dá sentido à educação porque responde aquela pergunta clássica do educando sobre o motivo para estar estudando algo. $\mathrm{O}$ "algo" na teoria freireana é o fio que une os dilemas e desejos do educando com os desafios de viver em sociedade. Une o que é interno com o que é-num primeiro momento - externo. 
Relaciona a dependência mútua dessas duas dimensões o que acaba por revelar que cada educando pode alterar o mundo porque ele é feito pela intervenção humana. Esta potência de mudança, de autoria, redefine o papel de cada um de nós. Não somos mais meros objetos, mas coautores do mundo. O estudo passa a ter sentido porque não se trata de memorizar algo que não compreendo para cumprir alguma exigência protocolar para seguir na vida. O estudo passa a me ajudar a ler ou ouvir o que outros procuraram explicar sobre este mundo. O estudo se torna uma ferramenta para explicar o mundo e para que eu ache um modo de interferir, como autor, neste mundo. Você poderia imaginar algo mais atual e poderoso que isso?

\section{Sobre os entrevistados:}

\section{CRISTIANO AMARAL GARBOGGINI DI GIORGI}

Possui graduação em Física pela Universidade de São Paulo, mestrado em Educação pela Pontifícia Universidade Católica de São Paulo e doutorado em Educação pela Universidade de São Paulo. Foi professor titular da Universidade Estadual Paulista Júlio de Mesquita Filho e professor do Programa de Pós-Graduação em Educação da Unoeste.

\section{DAGMAR MARIA LEOPOLDI ZIBAS}

É graduada em Pedagogia pela Universidade Presbiteriana Mackenzie, mestre em Educação pela Pontifícia Universidade Católica de São Paulo e doutora em Educação pela Universidade de São Paulo. Atuou como pesquisadora da Fundação Carlos Chagas de 1983 até 2008, quando se aposentou.

\section{RUDÁ GUEDES MOISES SALERNO RICCI}

É graduado em Ciências Sociais pela Pontifícia Universidade Católica de São Paulo, mestre em Ciência Política e doutor em Ciências Sociais pela Universidade Estadual de Campinas. Atualmente é presidente do Instituto Cultiva, consultor do Sindireceita, Sinesp, SindUTE e ATENs. É autor dos livros Terra de Ninguém (Editora Unicamp), Lulismo (Editora Contraponto), Nas Ruas: a nova política que emergiu em junho de 2013 (Editora Letramento), Os Desafios do Educador (Editora Letramento) e Conservadorismo Político em Minas Gerais (Editora Letramento). 